\title{
PEMODELAN MAJALAH INTERNAL BIDANG PARIWISATA DALAM MENDUKUNG KEGIATAN EDUKASI PARIWISATA DI DKI JAKARTA
}

\author{
Ikbal Rachmat, Erna Febriani, Muh. Ruslan Ramli, Robik Maulana, Mariana Evi Mantika, \\ Windi Widyawati, Stefhanny Pradisti, Sophian Hadi Wijaya, Yosheila, Thao Hong, \\ Ayub Aji Nugroho \\ Fakultas Ilmu Komunikasi, Universitas Esa Unggul, Jakarta \\ Jln. Arjuna Utara Nomor 9, Tol Tomang, Kebun Jeruk, Jakarta - 11510 \\ ikbal.rachmat@esaunggul.ac.id
}

\begin{abstract}
In carrying out its duties, the DKI Jakarta Tourism and Creative Economy Agency (DISPARTIF) has several responsibilities related to management of tourist attractions, management of strategic tourism areas, management of tourism destinations and implementation of data and information management as well as the development of tourism and creative economy in DKI Jakarta. This community service activity aims to provide a proposal for modeling an internal magazine in the field of tourism in supporting tourism education activities in DKI Jakarta by providing a touch of communication in terms of design on the appearance and layout and composition of the contents in internal magazines, so that it will bring out a stronger character in the internal magazine. one of these media can be used as a form of print media that is capable of presenting information in the field of tourism and the creative economy in DKI Jakarta. Methods of activities carried out by in-depth unstructured interviews and magazine-related modeling. The result of the final activity is in the form of internal magazine modeling in the field of tourism and creative economy in DKI Jakarta, namely in the form of a redesign covering the cover, the contents of the magazine which are developed with several aspects of coverage related to conducting interviews with several resource persons, recommended culinary destinations from menu to location. The contents of the magazine are also equipped with several UMKM or retail that carry out promotions on magazines and several other aspects in supporting the educational activities of the DKI Jakarta Tourism and Creative Economy Office.
\end{abstract}

Keywords : Internal magazine modeling, DISPARTIF, DKI jakarta

\begin{abstract}
Abstrak
Dalam melaksanakan tugas, Dinas Pariwisata dan Ekonomi Kreatif(DISPARTIF) DKI Jakarta memiliki beberapa tanggung jawab terkait pengelolaan daya tarik wisata, pengelolaan kawasan strategis pariwisata, pengelolaan destinasi pariwisata dan pelaksanaan pengelolaan data dan inforrnasi serta pengembangan kepariwisataan dan ekonomi kreatif di DKI Jakarta. Kegiatan pengabdian pada masyarakat ini bertujuan memberikan usulan pemodelan majalah internal bidang pariwisata dalam mendukung kegiatan edukasi pariwisata di DKI Jakartadengan memberikan sentuhan komunikasi dari segi desain pada tampilan serta tata letak maupun komposisi isi dalam majalah internal, agar lebih memunculkan karakter yang kuat pada majalah internal agar salah satu media ini dapat dijadikan bentuk karya media cetak yang mumpuni dalam menyajikan informasi bidang pariwisata dan ekonomi kreatif di DKI Jakarta. Metode kegiatan yang dilakukan dengan dengan wawancara mendalam tidak terstruktur danpemodelan terkait majalah.Hasil kegiatan akhir berupa pemodelan majalah internal bidang pariwisata dan ekonomi kreatif di DKI Jakarta yakni berupa redesign meliputi cover, isi majalah yang dikembangkan dengan beberapa aspek liputan terkait dengan melakukan wawancara kepada beberapa nara sumber, destinasi kuliner yang di rekomendasi mulai dari menu hingga lokasi. Isi majalah juga dilengkapi dengan beberapa UMKM ataupun retail yang melakukan promosi pada majalah dan beberapa aspek lainnya dalam mendukung kegiatan edukasiDinas Pariwisata dan Ekonomi Kreatif DKI Jakarta.
\end{abstract}

Kata kunci : Pemodelan majalah internal, DISPARTIF, DKI jakarta

\section{Pendahuluan}

Pada era keterbukaan informasi saat ini, dengan berbagai media massa yang terbit, melakukan penyiaran baik yang bersifat tercetak, dengan unsur audi, audio visual hingga multimedia melalui teknologi internet memberikan banyak kemudahan bagi siapapun untuk memperoleh informasi. Beragam informasi disajikan bukan saja dalam sendi bidang kehidupan namun hingga informasi yang bersifat privasi/personal dapat diperoleh.

Hal ini memberikan gambaran bahwa dengan kemajuan teknologi bidang komunikasi dan informasi, dengan adanya media baru melalui 
sambungan internet, kapanpun dimanapun kita dapat mengakses informasi dengan mudah, dengan beragam bentuk isi yang ditawarkan dari penyedia informasi.

Salah satu informasi yang sering di akses di antaranya informasi terkait destinasi wisata, negara, daerah, lokasi hingga beragam budaya, kuliner dan hiburan serta akses yang ditawarkan menjadi salah satu pilihan dalam membaca, meski layanan yang banyak dimanfaat saat ini melalui media internt seperti media sosial dan sebagainya.

Setiap media meiliki karakteristik yang berbeda satu dengan lainnya, media cetak memiliki akses terbatas pembacanya namun secara materi media ini mudah dibawa kemana-mana dan dapat di baca berulang kali, salah satu bentuknya adalah majalah. Majalah menyajikan informasi yang lebih spesifik (dapat membahas khusus bidang tertentu), desain yang lebih menarik karena biasanya fullcolour, hingga sajian layout/tata letak yang di padu padankan antara tulisan dan gambar sehingga memiliki daya tarik tersendiri.

DKI Jakarta, sebagai Ibukota negara Republik Indonesia tentunya memiliki daya tarik tersendiri. Dengan heterogennya penduduk, beragamnya bidang pekerjaan hingga terdapatnya beberapa situs peninggalan zaman kolonialisme karena sempat menjadi destinasi penjajah di masa lampau, memiliki daya tarik yang tinggi untuk diselami.

Dinas Pariwisata dan Ekonomi Kreatif Provinsi DKI Jakarta saat ini telah memiliki ruang informasi baik cetak maupun digital, namun dari segi penyajian masih di rasa perlu sentuhan komunikasi dan desain yang lebih menarik dalam medianya, sehingga kegiatan Pengabdian Pada Masyarakat ini terkait pemodelan majalah internal bidang pariwisata dalam mendukung kegiatan edukasi pariwisata di DKI Jakarta dapat menjadi nilai tambah bagi Dinas Pariwisata dan Ekonomi Kreatif DKI Jakarta untuk mengexpose DKI atas segala hal yang menjadi karakter wilayah utamanya dalam tatanan pariwisata dan ekonomi kreatif.

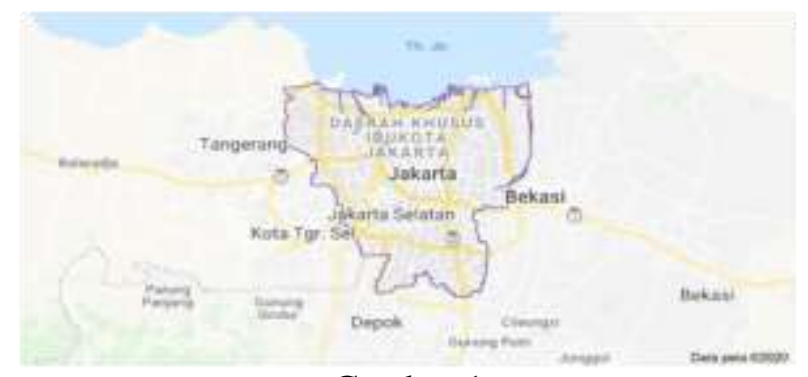

Gambar 1

Peta DKI Jakarta

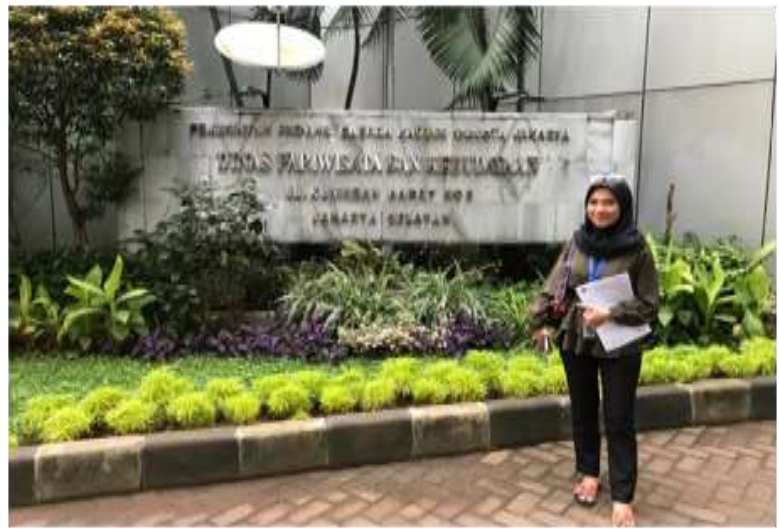

Gambar 2

Halaman Dinas Pariwisata dan Ekonomi Kreatif DKI Jakarta

Dari uraian keadaan lingkungan terkait destinasi wisata baik alam maupun indoor/dalam wilayah tertentu, kuliner, akses fasilitas umum, peta wilayah, bantuan informasi, tempat bersejarah, dan hal lainnya terkait pariwisata dan ekonomi kreatif dapat di lihat menjadi lebih menarik terkai hal tersebut di atas, Universitas Esa Unggul melalui Fakultas Ilmu Komunikasi mengadakan program pengabdian pada masyarakat melalui pemodelan majalah yang nantinya akan menjadi bagian dari kegiatan edukasi dan pariwisata di DKI Jakarta, yang dalam lingkup sosial dapat menggambarkan heterogennya suku, agama, ras yang berdomisili di DKI Jakarta dengan sajian beragam kuliner khas daerah, dan tentu menggambarkan kehidupan alkuturasi budaya dengan beragam profesi dan kesehariannya yang saling bersahaja.

\section{Metode Pelaksanaan}

Kegiatan pengabdian pada masyarakat ini dilaksanakan melalui beberapa tahapan dalam kurun waktu enam bulan yaitu Januari 2020 sampai Juli 2020. Tahap kegiatan ini dimulai dengan melakukan audiensi dengan pejabat Dinas Pariwisata dan Ekonomi Kreatif DKI Jakarta yang dalam hal ini di terima oleh Sekretaris Dinas Pariwisata dan Ekonomi Kreatif DKI Jakarta, dilanjutkan dengan penandatanganan MoA bersama untuk pelaksanaan kegiatan.

Kegiatan pemodelan majalah internal Dinas Pariwisata dan Ekonomi Kreatif DKI Jakarta ini dilaksanakan dengan melakukan pemilihan (secara random) yang mewakili khazanah pariwisata berupa : tempat/destinasi wisata, destinasi favorit tempat makan/wisata kuliner berkumpul yang nyaman, agenda ataupun kegiatan yang akan diselenggarakan di DKI Jakarta.

Setelah kegiatan mapping ini selesai dilakukan tim melakukan rapat redaksi guna merencanakan persiapan produksi media cetak yang meliputi : perencanaan terkait rapat redaksi 
penerbitan internal dan rubrikasi, pengumpulan informasi dan peliputan, pengolahan informasi dari penulisan naskah, desain, penyuntingan dan pencetakan serta distribusi.

Kegiatan pemodelan ini dilaksanakan dengan metode desain ekperimental dengan pembuatan model/bentuk rupa majalah. Format pembuatan model ini dilaksanakan dengan mengikuti standardimensi media cetak, khususnya majalah. Berikut tahapanyang dilakukan sebagai berikut :

1. Perencanaan

Kegiatan ini diawali dengan rapat redaksi terkait penerbitan internal dan perencanaan isi dan rubrikasi, diantaranya dengan membuka ruang diskusi dengan Sekretaris DISPARTIF DKI Jakarta, yakni Bapak Gumilar Ekalaya, SH., SE., M.SE. dan KasudinKebudayaan Jakarta Utarayakni Bapak Asiantoro sebagai upaya awal mendapatkan insight terkait pemodelan majalah internal.

2. Pengumpulan Informasi

Pada tahap ini meliputipengumpulan data base/contentinformasi atau peliputan wawancara/reportase dan liputan visual berupa foto dan atau perekaman yang disesuaikan dengan kebutuhan majalah sesuai karakter yang akan di buat, komunikasi antar personal dengan berbagai pihakmelalui wawancara mendalam tidak terstrutur, terkait informasi yang diperlukan dengan panduan bahan wawancara. Melakukan pemilihan (secara random) yang mewakili khazanah pariwisata berupa : tempat/destinasi wisata, destinasi favorit tempat makan/wisata kuliner berkumpul yang nyaman, agenda ataupun kegiatan yang akan diselenggarakan di DKI Jakarta.

3. Pengolahan Informasi

Kegiatan pengolahan informasi meliputi proses penulisan naskah, pemodelan/desain majalah berupa tata letak/lay out, penyuntingan naskah, pencetakan dengan pembuatan dummy dan cetak akhir.

\section{Distribusi}

Kegiatan ini umumnya terkait dengan pengiriman majalah, namun karena tidak di distribusikan secara komersil, majalah internal ini hanya diperuntukan untuk lingkungan organisasi dan atau pihak pihak tertentu yang perlu di distribusikan.

\section{Lokasi dan Jadwal Kegiatan}

Kegiatan pengabdian pada masyarakat ini (P2M) dilaksanakan pada Dinas Pariwisata dan Ekonomi Kreatif DKI Jakarta (DISPARTIF) yang beralamat di Jl.Kuningan Barat No.2, Jakarta Selatan 12710 Telp: +62 215205455 dan Universitas Esa Unggul sebagai lokasi utama kegiatan keredaksian majalah yang berlamat di Jl. Arjuna Utara, Kebon Jeruk No. 9, Jakarta Barat.

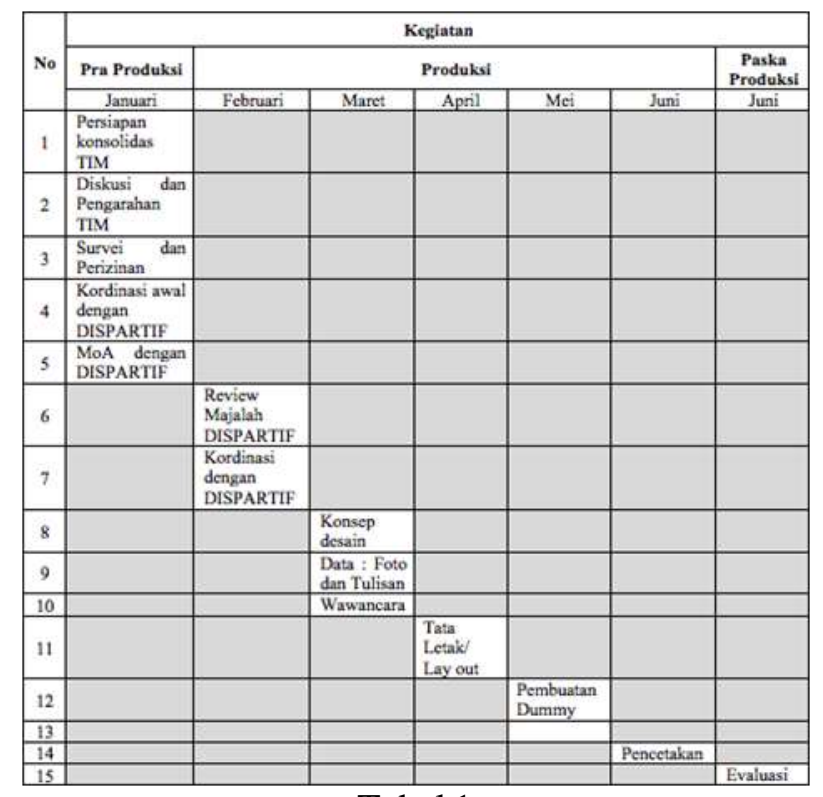

Tabel 1

Jadwal Kegaiatan

\section{Hasil dan Pembahasan}

Kegiatan pengabdian pada masyarakat ini meliputi 4 tahapan, yakni: perencanaan, pengumpulan informasi, pengolahan informasi dan distribusi. Adapun mitra dalam kegiatan ini yakni Dinas Pariwisata dan Industri Kreatif (DISPARTIF) DKI Jakarta. Adapun peserta dalam kegiatan ini yakni kelompok kerja praktek mahasiswa, dan dosen pembimbing yang berasal dari Fakultas Ilmu Komunikasi Universitas Esa Unggul dan mitra yang dalam hal ini Dinas Pariwisata dan Ekonomi Kreatif DKI Jakarta.

Dalam kegiatan perencanaan dilakukan penyampaian maksud dan tujuan pelaksanaan melalui diskusi awal dari beberapa perwakilan mahasiswa kepada Sekretaris DISPARTIF DKI Jakarta. Sambutan hangat dan izin diberikan sebagai langkah awal kegiatan pengabdian pada masyarakat dalam pemodelan majalah internal bidang pariwisata dalam mendukung kegiatan edukasi pariwisata di DKI Jakarta.

Berdasarkan hasil diskusi awal beberapa kesepakatan yang diperoleh antara lain diberikannya MoA sebagai wujud komitmen pelaksanaan kegiatan dan rekomendasi baik berupa kebutuhan isi konten maupun rujukan kegaiatan wawancara yang dilakukan berikutnya.

Kegiatan diskusi awal juga dilakukan dengan menemui Kasudin Kebudayaan Jakarta Utara yakni Bapak Asiantoro dalam upaya mendapatkan 
insight untuk majalah internal pada DISPARTIF DKI Jakarta.

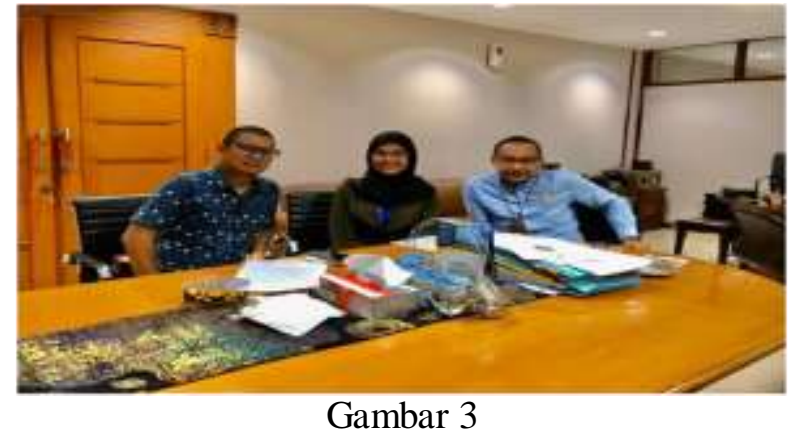

Diskusi awal bersama Sekretaris DISPARTIF DKI Jakarta

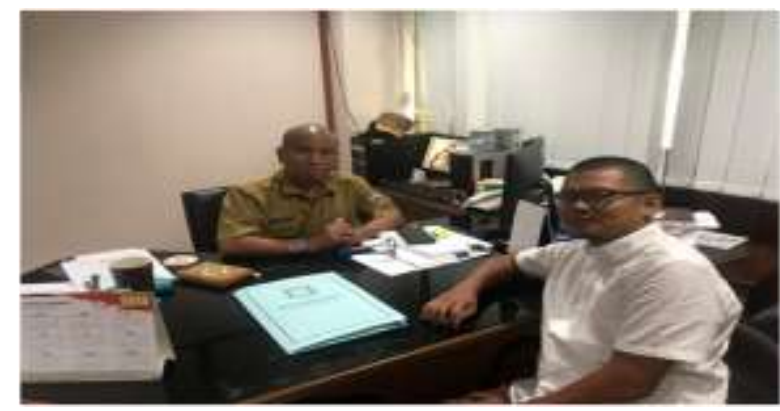

Gambar 4

Diskusi bersama Kasudin Kebudayaan Jakarta Utara

Setelah kegiatan diskusi awal dilaksanakan, untuk menindaklanjutinya tim melakukan kegiatan keredaksian. Kegiatan ini berupa beberapa kegiatan yang meliputi persiapan penerbitan media.

Kegiatan diawali dengan rapat redaksi. Dalam rapat redaksi tim melakukan pengumpulan data base/contentsebagai rubrik yang menjadi daftar isi dari majalah yang akan dibuat.

Kegiatan dilanjutkan dengan perencanaan isi dan rubrikasikebutuhan majalah sesuai karakter yang akan di buat dengan memberikan masukan dalam rapat redaksi yang secara garis besar meliputi :

Masthead/nameplate, berisikan informasi tentang penerbitan yang dalam hal ini yakni DISPARTIF susunan para redaktur, dan redaksi (pengarah atau penyunting), alamat, nama percetakan, dan nomor penerbitan sebagainya yang dianggap perlu untuk dicantumkan. Kolom masthead tersebut di halaman depan dan dalam bentuk kolom khusus.

Daftar isi majalah dalam pemodelan ini menggunakan istilah index yang memuat judul tulisan, rubrik, dan kolom berita, laporan, artikel hiburan, atau pengetahuan, tokoh, surat pembaca, dan lain sebagainya termasuk jadwal penerbitannya.

Kolom pembuka berisikan pengantar dari meja penerbit, pada pemodelan majalah internal DISPARTIF menggunakan nama Pengantar Tim Redaksi, dengan menyuguhkan pengantar
bahwaJAKWIZZ MAGAZINE adalah satu-satunya majalah yang menjadi partner Dinas Pariwisata Dan Ekonomi Kreatif DKI Jakarta dalam memberikan informasi serta liputan terupdate dalam pemberitaan tempat- tempat wisata, serta informasi terkini yang menjadi penunjang utama pariwisata. Kuliner, fashion, budaya, dan serta tempat-tempat wisata baru.

Sampul muka dan belakang (cover) sebagai daya tarik dilengkapi gambar atau ilustrasi yang menarik dengan kualitas kertasterbaik.

Editorial atau tajuk rencana yakni memuat bahasan atau pernyataan sikap dan opinidari pimpinan penerbit atau redaksi tentang sesuatu yang sedang aktual, faktual,dan informasi tengah dibicarakan oleh majalah. Pada edisi perdana majalah internal Jakwizz DISPARTIF mengetengahkan bahwa Banyak warga Jakarta yang awalnya berharap bisa memanfaatkan waktu liburnya dari berbagai aktifitas,ternyata mendapat kejutan dari kondisi cuaca yang ternyata tidak bersahabat. Banyak area pemukiman penduduk, area publik, pasar swalayan, mall bahkan tempat wisata yang terkena dampak banjir. Namun kejadian banjir kemarin bukan menjadi penghalang bagi kita untukterus semangat berada di Jakarta dengan segala kompleksitasnya.

Jakarta yang mengandalkan Pendapatan Asli Daerah (PAD) dari sektor jasa, terutama jasa hiburan dan priwisata sangat berbenah diri dalam menghadapi situasi pasca banjir awal tahun 2020 ini. Melalui Dinas Pariwisata Dan Ekonomi Kreatif DKI Jakarta, persoalan hiburan danpariwisata di tata ulang dengan menggandeng banyak pihak guna menggairahkan kembali bisnis hiburan dan pariwisata di Ibukota.

Terdapat iklan yang terpasang pada majalah Jak-Wizz, tetapi dibatasi sekitar 10 persen dari jumlah halaman seluruhnya. Dengan menggunakan bahasa Indonesia Jurnalistik yang benar.

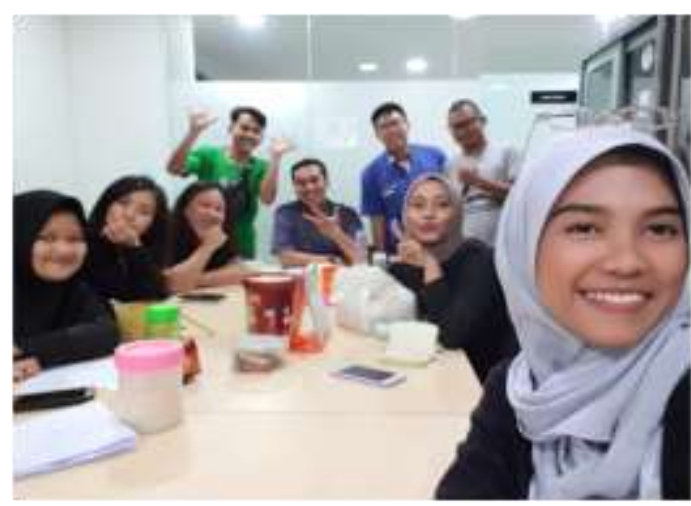

Gambar 5

Rapat Redaksi

Kegiatan berikutnya yakni melakukan pengumpulan informasi. Pada tahap ini meliputi pengumpulan data base/contentinformasi atau 
peliputan wawancara/reportase dan liputan visual berupa foto dan atau perekaman yang disesuaikan dengan kebutuhan majalah sesuai karakter yang akan di buat, komunikasi antar personal dengan berbagai pihak melalui wawancara mendalam tidak terstrutur, terkait informasi yang diperlukan dengan panduan bahan wawancara. Melakukan pemilihan (secara random) yang mewakili khazanah pariwisata berupa : tempat/destinasi wisata, destinasi favorit tempat makan/wisata kuliner berkumpul yang nyaman, agenda ataupun kegiatan yang akan diselenggarakan di DKI Jakarta

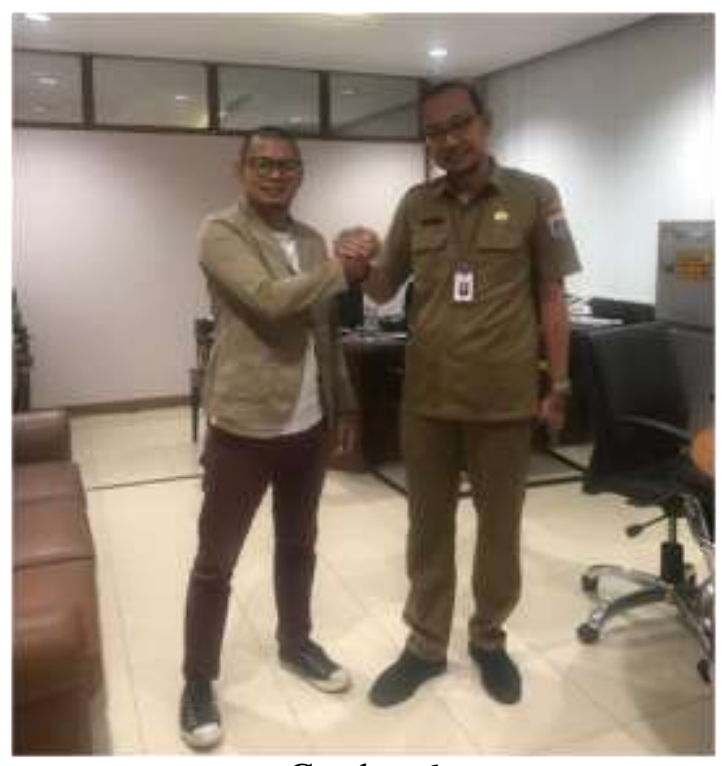

Gambar 6

Wawancara dengan sekretaris DISPARTIF

Dalam kegiatan wawancara salah satunya menjadi rubrik liputan khusus pada majalah internal oleh sekretaris DISPARTIF DKI Jakarta Bapak Gumilar Ekalaya, SH., SE., M.SE. dengan mengetengahkan wawancara terkaitperencanaan calender of event yaitu Festival sepanjang tahun dimana festival sepanjang tahun ini adalah festival-festival yang ada di Jakarta baik itu eventnya swasta, komunitas, pemerintah.

Wawancara dilanjutkan dengan penjelasan kegiatan event hiburan dan pariwsata di Jakarta akankah di akomodir oleh dinas bahwa semua akan di akomodir,siapapun penyelenggaranya. Dalam festival sepanjang tahun itu akan bagi dalam 3 kategori, yaitu lokal Jakarta, nasional dan internasional serta FestivalSepanjang Tahun ini akan ada websitenya.

Terkait dengan wawancara koordinasi dengan Kementrian Pariwisata dan EkonomiKreatif, bahwa koordinasi, rutin dilakukandiamana ada juga event yang sifatnya nasional, yang di buat kementrian selain itu kordinasi rutin dilaksanakan menjaga program.
Terkait pemisahan antara dua lembaga yaitu pariwisata dan kebudayaan, dimana yang lalu masih pakai nama Dinas Pariwisata \& Kebudayaan, bahwa karena dirasa terlalu berat dari sisi fokus kerjanya memang ada yang berbarengan tapi juga ada yang bertolak belakang. Kebudayaan itu lebih pada pembinaan, kelestarian, pengembangan sementara kalau Pariwisata itu kaitanya dengan profit, bagaimana mendatangkan wisatawan, menaikkan sektor pariwisata, gimana tempat wisata penuh, gimana turis yang berkunjung ke Jakarta, maka dari itu dipisahkan agar ada fokus kegiatanya.

Sebagai pamungkas liputan terkait wawancara perihal komunitas hasil dari pembinaan oleh Dinas Kebudayaan akankah di ikut sertakan dalam event pariwisata, pastinya, nanti outputnya dari hasil pembinaan yang dilakukan kebudayaan akan dibawa ke event-event promosi daerah dan luar negeri yang diagendakan.

Tahapan pengolahan informasi dimana meliputi proses penulisan naskah, pemodelan/desain majalah berupa tata letak/lay out, penyuntingan naskah, pencetakan dengan pembuatan dummy dan cetak akhir.

Kegiatan ini kembali di awali dengan rapat redaksi kembali tim untuk mendistribusikan tugas pada masing - masing proses.

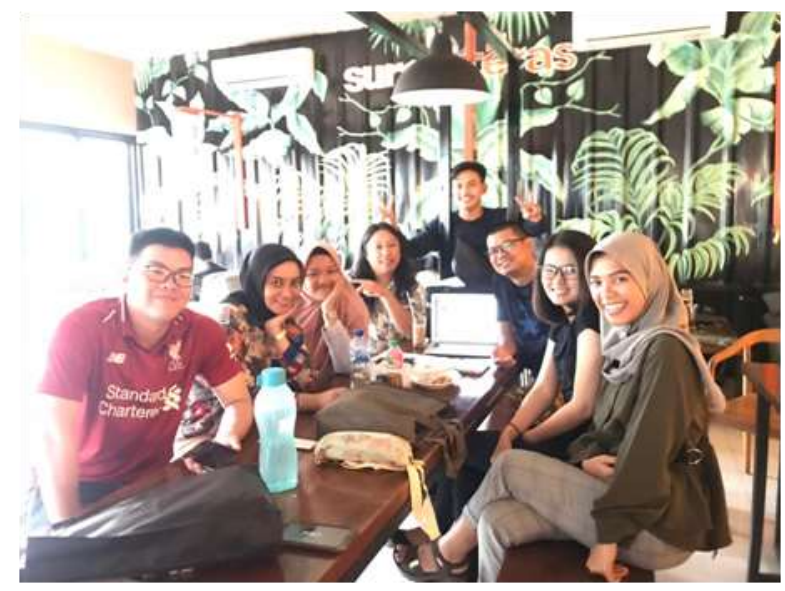

Gambar 7

Rapat pengolahan informasi

Secara umum bentuk naskah majalah internal berbentuk berita, khususnya beritafeature, yang secara penyajian tidak harus segera disiarkan/ dapat di tunda dan ringan yang tidak memerlukan unsur berfikir secara mendalam. Susunan pemodelan majalah internal Jak-Wizz DISPARTIF DKI Jakarta meliputi : 
Tabel 2

Struktur Pemodelan Majalah Jak-Wizz

\begin{tabular}{|c|c|c|c|c|}
\hline No & $\begin{array}{l}\text { Nomor } \\
\text { Halaman }\end{array}$ & Isi/Rubrik & Sub konten & Deskripsi Rubrik \\
\hline 1 & Halaman 1 & Cover & & \\
\hline 2 & Halaman 2 & Index & & $\begin{array}{l}\text { Index menyuguhkan halaman beserta } \\
\text { rubriknya. }\end{array}$ \\
\hline 3 & Halaman 3 & Tim Redaksi & & $\begin{array}{l}\text { Halaman ini berisi jajaran nama dan } \\
\text { jabatan tim redaksi serta kelanjutan } \\
\text { halaman beserta rubriknya. }\end{array}$ \\
\hline 4 & Halaman 4 & $\begin{array}{l}\text { Pengantar } \\
\text { Redaksi }\end{array}$ & & $\begin{array}{l}\text { Pengantar redaksi memberikan pendapat, } \\
\text { opini dan pendapat secara umum } \\
\text { mengenai isi pemberitaan majalah Jak- } \\
\text { Wizz }\end{array}$ \\
\hline 5 & $\begin{array}{l}\text { Halaman } 5- \\
8\end{array}$ & $\begin{array}{l}\text { Rubrik } \\
\text { Liputan } \\
\text { Budaya }\end{array}$ & & $\begin{array}{l}\text { Berisi hasil liputan sebuah destinasi } \\
\text { wisata yang di kupas muali dari lokasi, } \\
\text { karakteristiknya hingga beberapa yang } \\
\text { menjadi keunikan pada destinasi wisata } \\
\text { tersebut. }\end{array}$ \\
\hline 6 & Halaman 9 & Iklan & & Umum \\
\hline 7 & $\begin{array}{l}\text { Halaman } \\
-13\end{array}$ & $\begin{array}{l}\text { Rubrik } \\
\text { Liputan } \\
\text { Terkini }\end{array}$ & & $\begin{array}{l}\text { Halaman ini memberikan deskripsi lokasi } \\
\text { - lokasi terupdate yang berada di jakarta, } \\
\text { bisa dari keunikan, kekhasan hingga hal- } \\
\text { 8hal lainnya yang menjadi daya ta9rik } \\
\text { kawasan tersebut. }\end{array}$ \\
\hline 8 & $\begin{array}{l}\text { Halaman } \\
-15\end{array}$ & $\begin{array}{l}\text { Rubrik } \\
\text { Liputan } \\
\text { Kuliner }\end{array}$ & & $\begin{array}{l}\text { Me10njadi halaman yang memberikan } \\
\text { ulasan liputan kuliner yang paling favorit } \\
\text { karena rasa, ramainya pengunjung hingga } \\
\text { harga maupun lokasi keberadaannya. }\end{array}$ \\
\hline 9 & $\begin{array}{l}\text { Halaman } \\
-19\end{array}$ & $\begin{array}{l}\text { Rubrik } \\
\text { Liputan } \\
\text { Wisata }\end{array}$ & & $\begin{array}{l}\text { Lokasi wisata di DKI menjadi pelengkap } \\
\text { sajian majalah Jak-wizz dimana lokasi ini } \\
\text { dapat berupa lokasi - lokasi wisata yang } \\
\text { paling banyak dikunjungi. }\end{array}$ \\
\hline 10 & Halaman 20 & Iklan & & Umum \\
\hline 11 & $\begin{array}{l}\text { Halaman } \\
-36\end{array}$ & $\begin{array}{l}\text { Rubrik } \\
\text { Sekilas Info }\end{array}$ & 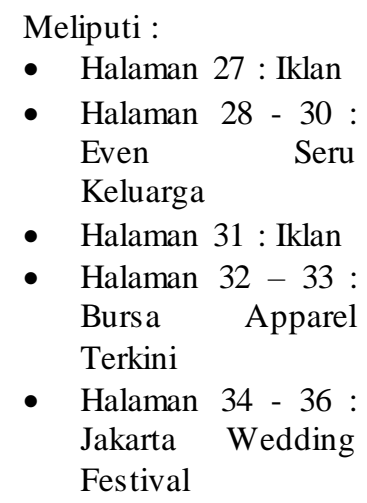 & $\begin{array}{l}\text { Sekilas info menyajikan halaman yang } \\
\text { penuh dengan informasi terupdate, } \\
\text { namun tidak dijabarkan dengan detil, } \\
\text { gunanya hanya memberikan high light }\end{array}$ \\
\hline 12 & Halaman 37 & $\begin{array}{l}\text { Rubrik } \\
\text { Liputan } \\
\text { Khusus }\end{array}$ & $\begin{array}{l}\text { Meliputi: } \\
\text { - Halaman } 38-40 \text { : } \\
\text { Yang Wajib di } \\
\text { Tonton } \\
\text { - Halaman } 41 \text { : Iklan }\end{array}$ & $\begin{array}{l}\text { Halaman liputan khusus menjadi karakter } \\
\text { majalah Jak-Wizz, dimana hasil liputan } \\
\text { yang menyajikan reportase khusus di } \\
\text { sajikan pada bagian akhir majalah, } \\
\text { tujuannya untuk menyuguhkan informasi } \\
\text { penting namun ringan, sehingga pembaca } \\
\text { masih konsisten untuk tetap membaca } \\
\text { majalah hingga akhir. }\end{array}$ \\
\hline 13 & $\begin{array}{l}\text { Halaman } \\
-45\end{array}$ & $\begin{array}{l}\text { Rubrik } \\
\text { Liputan } \\
\text { Jakarta }\end{array}$ & & $\begin{array}{l}\text { Sebagai karakter majalah Jak-Wizz } \\
\text { lainnya, sajian terkait Kota Jakarta juga } \\
\text { tetap dihadirkan, seputar pemberitaan } \\
\text { yang menjadi informasi ringan. }\end{array}$ \\
\hline
\end{tabular}


14 Halaman 46 Calendar of - 49 Event
Bagian akhir dari majalah Jak-Wizz memberikan sajian informasi agenda kegiatan yang akan akan diselenggarakan selama kurun waktu satu tahun berjalan, yang tentunya menjadi rutinitas program kerja ataupun event suku dinas, khususnya DISPARTIF DKI Jakarta. Umum
Susunan tersebut di tuangkan dalam desain dan lay out/tata letak yang pada akhirnya digunakan sebagai pemodelan. Sebelum kegiatan desain di buat, tim saling memberikan masukan sebagai bahan pertimbangan, tentu dengan melihat elemen desain grafis yakni bentuk, warna, ilustrasi, huruf, layout, software dan media menjadi elemen kuat dan prinsip desain grafis yakni metaphor/kiasan, clarity/ kejelasan, dan consistency/ketetapan pun menjadi dasar diskusi.

Selain elemen dan prinsip desain grafis, format tata letak yang meliputi jenis tata letak vertikal, horizontal dan diagonal juga digunakan, dan prinsip dasar desain turut andil sebagai rujukan pemodelan majalah, yakni keseimbangan, adalah Kesamaan dari unsur-unsur saling berlawanan, tetapi salingmelengkapi dan membentuk satu kesatuan yang seimbang., dalam pemodelan ini visual ilustrasi cover majalah Jak-Wizz berada pada keseimbangan horizontal, vertikal maupun radial, yang berfungsi untuk tampilan formal cover dengan suasana sebuah ruang makan yang lapang dengan frame sebagai pemisah anatar ruang dalam dan luar. Proporsi merupakan perbandingan obyek- obyek satu dengan yang lainnya, dilihat dari keseluruhan obye pada desain cover majalah Jak-Wizz utamanya dengan adanya bingkai antar ruang diupayakan pada susut dengan proposional, dengan pembagian kotak kotak persegi.Iramaadalah kesan gerak yang timbul karena adanya keselarasan unsur-unsur seni rupa yang tersusun dalam sebuah komposisi dalam desain cover kemunculan bagian ruang dalam dalam sebuah bingkai kotak tersendiri, lebih dominan dibanding dengan kotak lainnya. Kesatuan adalah paduan unsur- unsur visual dengan karakter yang berbeda harus ada dalam kesatuan yang saling mengisi agar tercapai karya yang sempurna dan berkualitas baik terdapat pada bagian halaman redaksi majalag JakWizz antara susunan tim redaksi dengan sebagian halaman daftar isi/index malajah. serta kontras yang merupakan perbedaan keadaan unsur-unsur atau antara organisasi unsur yang dapat dicapai dengan perbedaan tinggi-rendah, panas-dingin warna, termasuk cerah dan suramnya, di mana dalam desain cover warna yang disajikan cenderung dengan kontras sedang, atau seimbang antara ilustrasi dengan warna cover majalah Jak-Wizz.
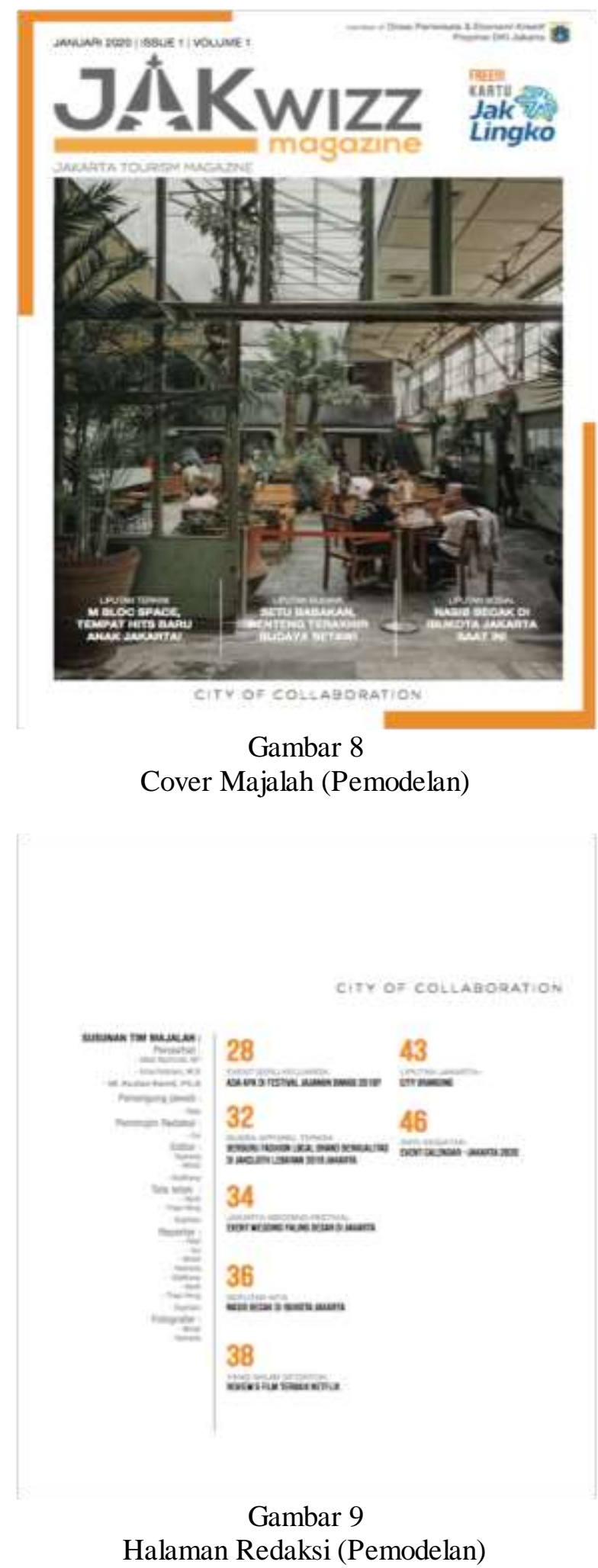
Berikut ini beberapa contoh pemodelan desain/lay out/tata letak coverdan halaman redaksimajalah Jak Wizz :

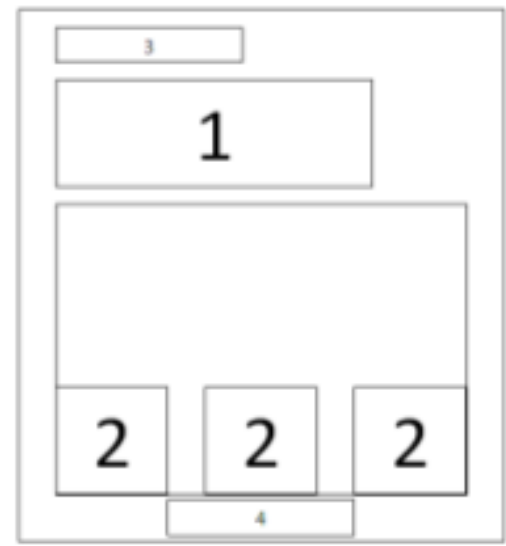

Gambar 10

Layout Cover

Layout Cover

Halaman 1 - Cover
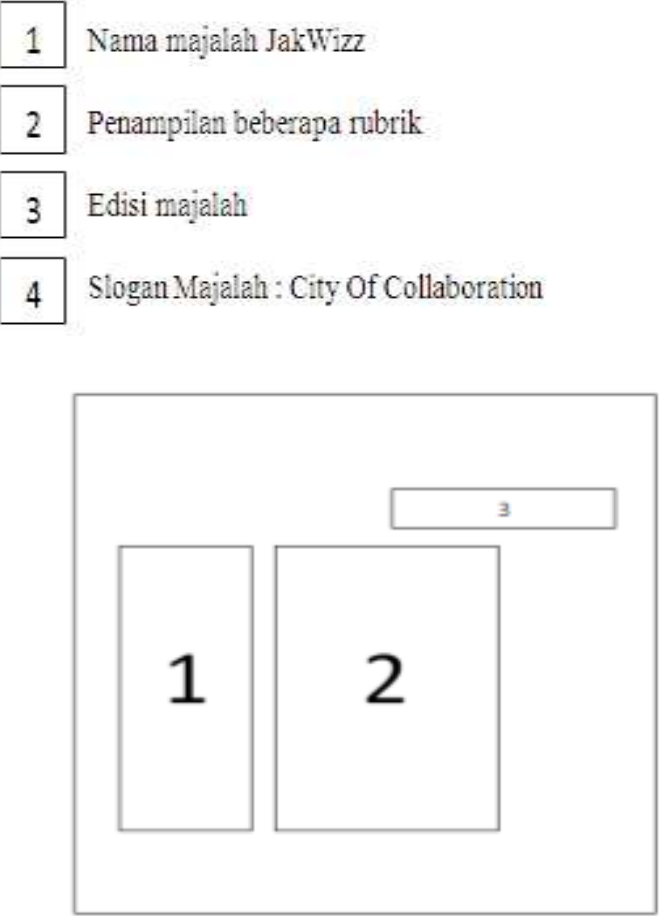

Gambar 11

Layout halaman tim redaksi

Halaman 2 - Tim Redaksi

1 Nama tim redaksi

2 Halaman rubrik

3 Slogan Majalah: City Of Collaboration

Kegiatan akhir pada rangkaian pemodelan majalah internal berupa distribusi majalah.
Kegiatan ini dilakukan dengan kegiatan pengiriman majalah, namun karena tidak di distribusikan secara komersil, majalah internal ini hanya diperuntukan untuk lingkungan internal organisasi dan atau pihak - pihak tertentu yang menjadi rekanan DISPARTIF DKI Jakarta, baik lembaga swasta, institusi pemerintah hingga komunitas.

\section{Kesimpulan}

Dari keseluruhan rangkaian kegiatan Pengabdian Pada Masyarakat (P2M) pemodelan majalah internal bidang pariwisata dalam mendukung kegiatan edukasi pariwisata di DKI Jakartayang telah dilaksanakan dapat diperoleh beberapa kesimpulan sebagai berikut :

1. Pemodelan majalah internal DISPARTIF merujuk pada 4 tahpan yang meliputi ; perencanaan, pengumpulan informasi, pengolahan informasi dan distribusi majalah.

2. Kegiatan pemodelan majalah internal DISPARTIF guna mendukung kegiatan edukasi khususnya bidang pariwisata di wilayah DKI Jakarta merujuk pada kekuatan karakter majalah yang diciptakan, dengan menyajikan informasi baik liputan umum maupun wawancara,mengikuti kaidah yang digunakan secara umum, diantaranya dengan bentuk naskah majalah internal berupa berita, khususnya kategori berita feature.

3. Desain tata letak/lay out mengacu pada prinsip - prinsip dasar desain yang meliputielemen desain grafis yakni bentuk, warna, ilustrasi, huruf, layout, software dan media menjadi elemen kuat dan prinsip desain grafis yakni metaphor/kiasan, clarity/kejelasan, dan consistency/ketetapan serta elemen dan prinsip desain grafis hingga prinsip dasar desain.

\section{Daftar Pustaka}

A.Fauziah Astrid. (2017). Eksistensi Media Internal Sebagai Alat Kehumasan (Studi Kasus Majalah Empati Psmp Toddopuli Makassar), $\quad$ http//journal.uinalauddin.ac.id/index.php/jurnalisa/article/vie w/3096

Ardianto, Elvinaro, Komala, dan Siti Karlinah. (2007). Komunikasi Massa Suatu Pengantar. Simbiosis Rekatama Media. Bandung.

Ayu Nazila. (2010). Proyek Majalah Internal Perusahaan PT. Kereta Api Daop IV Semarang, http://eprints.undip.ac.id/24953/ 
Azka Destriawan. (2018). Produksi Majalah

Tentang Proses Kreatif Street Art dan Penguatan Eksistensi Komunitas Street Art di Yogyakarta, https://dspace.uii.ac.id/handle/123456789/10 295

data.jakarta.go.id, 2020.

Dinas Pariwisata dan Ekonomi Kreatif DKI Jakarta, 2020.

Fadmi Nanda Putri Hardi. (2017). Aktivitas Tenant Relations Dalam Mengelola House Journal (Mp Magazine) Sebagai Upaya Meningkatkan Corporate Image Pada Mal Pekanbaru, http://repository.uinsuska.ac.id/20839/

Frizqi Andhesta Iswaldy. (2020). Proses Produksi Majalah Fokus Di Bank Indonesia, http://ereport.ipb.ac.id/id/eprint/1509/1/J3A 117189-01-Frizqi-Cover.pdf

Hendratman, Hendi. (2014). Computer Graphic Design. Jakarta : Informatika.

(2014). The Magic of Corel Draw. Jakarta: Informatika.

Morissan. (2007). Periklanan; Komunikasi Pemasaran Terpadu, Jakarta: Ramdina Prakarsa.

Nurudin. (2009). Jurnalisme Masa Kini, Jakarta : Rajawali Pers.

Baran, Stanley J. Pengantar Komunikasi Massa Jilid I Edisi 4. PT Gelora Aksara Pratama. Jakarta.

Ruslan, Rosady. (2010). Manajemen Public Relations dan Media Komunikasi. Jakarta : Rajagrafindo Persada.

Yosef, Jani. (2009). To Be A Journalist, Menjadi Jurnalis Tv, Radio, dan Surat Kabar yang Profesional. Yogyakarta : Graha Ilmu. 